\title{
Avaliação da associação de compósito de fibra de vidro e carbono no reforço de madeira de eucalyptus in natura e autoclavada
}

\author{
G. MOHAMAD ${ }^{\mathrm{I}}$; J. ACCORDI ${ }^{\mathrm{I}}$; L.E. ROCA ${ }^{\mathrm{I}}$; \\ ${ }^{\mathrm{I} C u r s o}$ de Engenharia Civil - Campus Alegrete - Av. Tiarajú 810, UNIPAMPA, Universidade Federal do \\ Pampa - Cep 97546-550, Alegrete, RS. \\ e-mail: gihad@unipampa.edu.br \\ ${ }^{\text {II } U n i v e r s i d a d e ~ d o ~ E x t r e m o ~ S u l ~ C a t a r i n e n s e, ~ C u r s o ~ d e ~ E n g e n h a r i a ~ C i v i l, ~ C r i c i u ́ m a, ~ S C . ~}$ \\ e-mail: juliana@mcapivaras.com.br ; roca_bruno@ hotmail.com
}

\begin{abstract}
RESUMO
Reforçar estruturas é uma prática que demanda conhecimento do sistema de reforço e do comportamento da estrutura interferida. A necessidade de recuperação e reforço em estruturas de madeira, em detrimento à troca das peças de um arranjo estrutural, exigiu da construção civil a procura por métodos eficientes e confiáveis. Dentre esses métodos tem se destacado o uso de fibras, sendo as de carbono, vidro e aramida as mais pesquisadas e utilizadas. Nesta pesquisa avaliou-se a associação da fibra de vidro e de carbono à madeira de Eucalyptus grandis in natura e autoclavada com o uso do adesivo epóxi, objetivando analisar a viabilidade técnica desse tipo de combinação no reforço de estruturas de madeira por meio da interpretação dos resultados de ensaios de tração e modos de ruptura. Definidas as variáveis, procederam-se os ensaios de tração direta nas amostras. Os resultados apontaram uma superioridade da fibra de carbono em relação às fibras de vidro quanto à tensão de ruptura. Com a aplicação da fibra de carbono em corpos de prova fraturados, obteve-se uma recuperação de $90 \%$ da resistência em comparação aos corpos de prova sem fraturas. Em relação ao substrato, de um modo geral, as madeiras de Eucalyptus in natura e autoclavada não apresentaram diferenças significas no desempenho quanto à aderência da resina epóxi.
\end{abstract}

Palavras chaves: Reforço, Estruturas de madeira, Fibra de carbono, Fibra de vidro.

\section{Evaluation of the association of glass and carbon fibers for strengthening of eucalyptus wood in natura and autoclaved}

\section{ABSTRACT}

The practice of structural strengthening demands knowledge about which methods can be used, as well as the behavior among evaluated materials. In the context of Civil Engineering, reliable methods are required for the recuperation and strengthening of woods structures. The most used fibers to recover historic buildings are carbon, glass and aramid fibers. Thus, the goal of this research was to evaluate the association of carbon and glass fiber with adhesive epoxy in woods as Eucalyptus grandis in natural and autoclaved using tensile tests and failure mode. We studied this kind of combination for strengthening wood structures using direct tensile test. Our results showed that carbon fiber is better than glass fiber considering failure mode. On the other hand, strengthening wood structures with carbon fiber recovered $90 \%$ of the tensile strength of the materials. Furthermore, Eucalyptus in natura and autoclaved did not present significant differences on their performances under tensile testing with reference to the adherence of the adhesive epoxy.

Keywords: Strengthening, Wood Structures, Carbon Fiber, Glass Fiber.

\section{INTRODUÇÃO}

Estruturas formadas por elementos de madeira têm aplicações em pontes, coberturas, vigas, mezaninos entre outros, onde o desempenho satisfatório desse tipo de material depende de variáveis como a concepção atribuída ao arquiteto, usos da edificação, qualidade das madeiras entre outros. Construções históricas, por exemplo, que tinham uma finalidade numa determinada época, hoje, em muitos casos necessitam de reforço para adequar-se às novas exigências de pesos acidentais. 
Atualmente, projetos de revitalização urbanística dos centros históricos requerem mudanças de uso dos imóveis. Para isso, é necessária a reabilitação das edificações de forma a resolver alguns problemas sociais como a ocupação desordenada (MIOTTO e DIAS [1] e CARVALHO [2]). Poucas são as construções que datam séculos e chegam até os tempos atuais com os materiais originais, onde o restauro e a reabilitação é fundamental para a preservação.

A madeira é um material que sofre degradação por ataques por fungos e cupins típicos do clima tropical brasileiro, comprometendo as diferentes características físicas e mecânicas das peças. A aplicação de sobrecargas, combinadas ou não com os ataques biológicos deformam as estruturas, diminuindo sua massa, peso e resistência. Portanto, o reforço em estruturas de madeira pode ser de grande valia para a recuperação e segurança estrutural de construções históricas. Por isso, é importante assegurar que se comportem adequadamente, sob pena de comprometer a estabilidade da edificação (ILHARCO et al, [3] ]). A vida útil média de uma estrutura de qualquer natureza pode ser conseguida e até mesmo ampliada desde que se disponha de uma manutenção preventiva adequada. Além da falta de manutenção, as estruturas podem apresentar vícios que afetam o seu desempenho que vão desde inadequada concepção estrutural e defeitos construtivos, até utilização para cargas de serviço incompatíveis com aquelas originalmente previstas (MACHADO [4]). Segundo FIORELLI e DIAS [్], usuários, projetistas e construtores devem conhecer o emprego e as características de um material antes de indicá-lo a um determinado uso e, isso também é válido para a madeira. A realização de inspeções periódicas com o intuito de atestar a conservação das estruturas de madeira, aplicadas com função estrutural, pode encontrar anomalias no comportamento destas estruturas. Portanto, as manifestações patológicas devem ser identificadas na sua origem e a relação que tem com a segurança e confiabilidade de uma obra. Em função disso, é possível definir sobre a conveniência da recuperação, do reforço ou mesmo a demolição. Em uma vistoria preliminar em estruturas de madeira, devem ser procurados indícios de má conservação dos elementos e sobrecargas, freqüentemente traduzidos em deformações acentuadas ou sintomas associados à umidade. Segundo CRUZ [6] , o aspecto exterior de uma construção permite fazer um levantamento destas anomalias e zonas problemáticas conforme mostra a Figura 1.

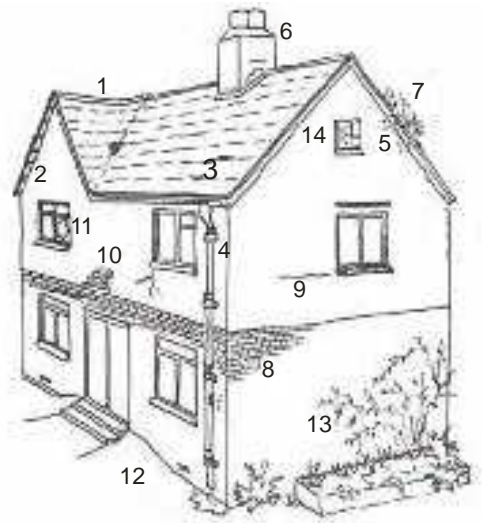

(1) Deformação (telhado,...)

(2) Madeira exposta em mau estado

(3) Telhas partidas ou em falta

(4) Condutores e calhas danificadas

(5) Telhado pouco saliente

(6) Remates ineficazes

(7) Crescimento de vegetação

(8) Manchas de umidade

(9) Fendas em paredes

(10) Rebocos desagregados ou fissurados

(11) Caixilhos deteriorados

(12) Falta de faixa impermeabilizante

(13) Canteiros adjacentes

(14) Aberturas de ventilação obstruídas

Figura 1: Pontos críticos em uma edificação. Fonte: CRUZ [6].

Após a identificação dos pontos críticos na edificação, que um modo geral está junto às fachadas, pode-se avaliar a gravidade da deterioração e, por conseqüência, elaborar um diagnóstico com a metodologia de correção, onde deve constar a natureza da madeira empregada e localização do elemento no conjunto estrutural. O diagnóstico deve sanar dúvidas como: qualidade da madeira (espécie florestal), interferência de agentes biológicos, seção resistente residual (útil), características do material encontrado (tensão e umidade), zonas atacadas, agentes causadores do problema e vícios construtivos. Em construções históricas, particularmente, os ensaios não destrutivos são os mais indicados para a elaboração desse diagnóstico, tais como as técnicas de ultra-som, pylodin, raios gama entre outras. Informações sobre a idade da edificação e história (ocupação, alterações, reparos) podem esclarecer possíveis situações (FEIO [7]). Uma recuperação na estrutura de madeira inicia com a secagem de possíveis fontes de umidade e limpeza da mesma, onde, posteriormente, deve-se executar um tratamento na madeira remanescente. Existem dois cenários distintos para a reparação de uma construção em madeira: (a) Reabilitação, quando são recompostas as condições normais de suporte; (b) Reforço, quando a condição de suporte é aumentada em relação àquela prevista anteriormente.

Os cupins subterrâneos vivem em colônias, constroem ninhos, podendo conter milhões de indivíduos que se desenvolvem preferencialmente no solo, ou seja, sempre existindo a necessidade de uma fonte úmida (ROMAGNANO [8]). As térmitas ou cupins subterrâneos são pertencentes a um grupo denominado Dictyoptera, que inclui também as baratas e o louva-a-deus (ROMAGNANO [8]). Um sinal 
freqüente da presença desses insetos é a ocorrência de revoadas, durante as quais centenas deles saem da madeira e voam para a luz, perdendo as asas e acasalando, podendo infestar outras madeiras e construções que apresentem temperatura e umidade propícias ao ataque. CRUZ [6] cita que o fungo apodrecedor desenvolve-se em madeira com teor de água superior a $20 \%$, mas não saturada por completo. A madeira atacada sofre alteração de cor e aspecto, além da perda de peso e resistência como mostra a Figura 2. A eliminação da fonte úmida e a secagem da madeira podem ser suficientes para cessar o ataque pelo fungo, sendo necessário posterior o tratamento preservador curativo, preventivo e reforço do elemento afetado.
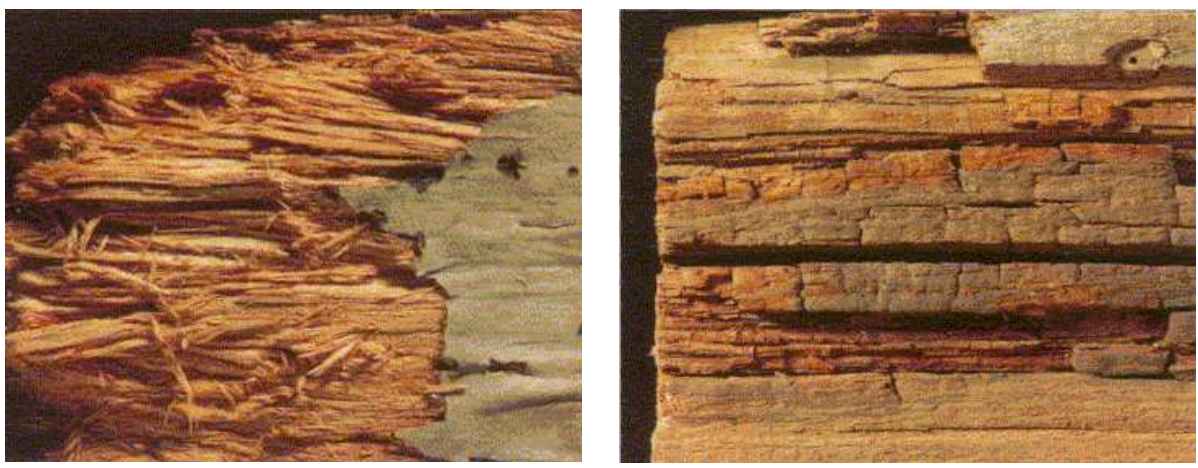

Figura 2: Aspectos da madeira atacada por fungos apodrecedores. Fonte: CRUZ [6].

A utilização de polímeros reforçados fibras (FRP) para reforço e recuperação de estruturas de madeira é uma tendência, afirma FIORELLI [9]. O reforço em estruturas de madeira pode ser preciso em ocasiões na qual o aumento de carga não foi previsto em projeto, ultrapassando o estado limite de utilização da estrutura. Essa sobrecarga pode originar-se na deterioração do conjunto devido à falta de manutenção e/ou umidade causada por infiltrações. Também podem ser causas às forças desenvolvidas por outros elementos nas estruturas em madeira, erro de cálculo estrutural, ataques químicos, envelhecimento e reparos devido a acidentes. Quanto à Forma e sentido da aplicação de fibras nas estruturas de madeira, segundo CUNHA e SOUZA [10] é mais vantajoso aumentar a espessura do reforço do que a largura. A Figura 3 apresenta uma seqüência da aplicação de fibra de carbono reforçada com polímero (CFPR) de um casarão histórico.
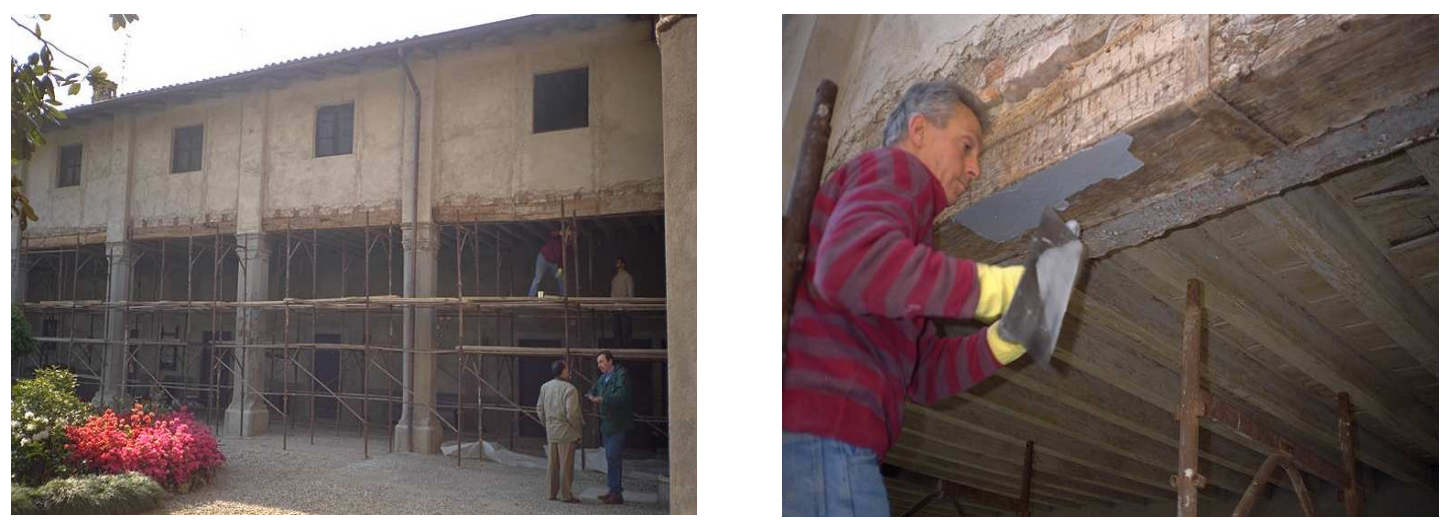

Figura 3: Vista Geral do casarão em recuperação. Fonte: SIKA [11] - Itália.

\section{MATERIAIS E MÉTODOS}

\subsection{Considerações iniciais}

A aplicação da manta de tecido é fundamental para o reforço em estruturas de madeira, sendo apresentada aqui a metodologia utilizada para a aplicação da fibra de carbono e vidro laminados com adesivo epóxi em corpos de prova de madeira da espécie Eucalyptus grandis sem e com tratamento em autoclave.

O objetivo principal deste trabalho é avaliar a eficiência do sistema (fibra/matriz) para o uso deste como reforço em estruturas de madeira no estado natural e com tratamento em autoclave. 


\subsection{Características dos Corpos-de-Prova}

Os corpos de prova utilizados são de madeira maciça conforme as Figuras 4 e 5, beneficiados exclusivamente para o ensaio de tração com formato semelhante ao definido na NBR 7190 [12]. O corte da madeira foi feito no sentido paralelo às fibras.

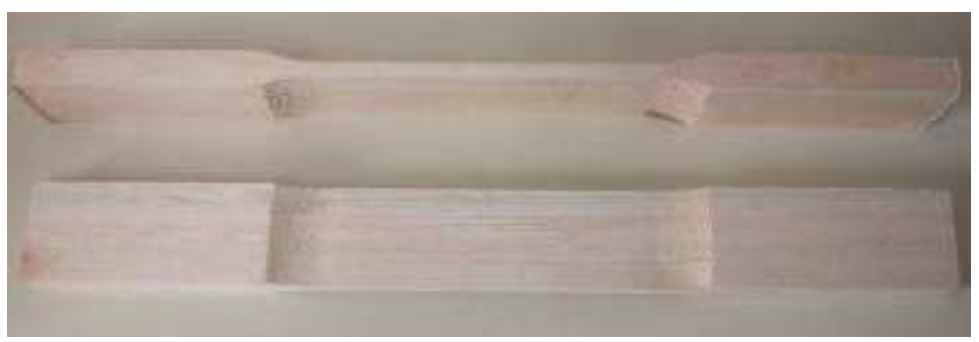

Figura 4: Corpo de prova confeccionado com madeira maciça.

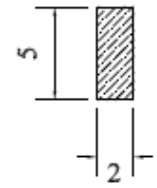

\begin{tabular}{|l|c|c|}
\hline \multicolumn{2}{|c|}{45} & 12 \\
\hline 12 & 21 & \\
\hline & & \\
\hline & & \\
\hline
\end{tabular}

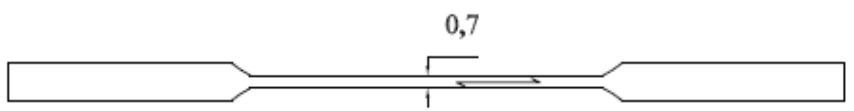

Figura 5: Dimensões de um corpo de prova para ensaio de tração.

Devido às limitações impostas pelo equipamento utilizado nos ensaios de tração direta, a seção transversal do corpo de prova com medidas de 50 por 20 milímetros foi reduzida para 50 por 18 milímetros. A redução deu-se em função da garra utilizada para segurar o corpo de prova durante o ensaio ter uma limitação na sua abertura. No entanto, a parte central do mesmo não foi alterada. A Tabela 1 mostra a distribuição dos corpos de prova de acordo com cada variável envolvida no programa experimental.

Tabela 1: Distribuição dos corpos de prova utilizados nos ensaios.

\begin{tabular}{c|c|c|c}
\hline \multicolumn{4}{c}{ Ensaios com corpos de prova sem reforço } \\
\hline Quantidade & Condição da madeira & \multicolumn{2}{c}{ Verificações do ensaio } \\
\hline 6 & $\begin{array}{c}\text { Sem tratamento } \\
\text { (In natura) }\end{array}$ & \multicolumn{2}{c}{ Resistência à tração e Modo de ruptura } \\
\hline 6 & $\begin{array}{c}\text { Com tratamento } \\
\text { (Autoclavada) }\end{array}$ & \multicolumn{2}{c}{ Resistência à tração e Modo de ruptura } \\
\hline \multicolumn{5}{c}{ Ensaios em corpos de prova reforçados com fibras } \\
\hline Quantidade & Condição da madeira & Tipo de reforço & Verificações do ensaio \\
\hline 6 & $\begin{array}{c}\text { Sem tratamento } \\
\text { (In natura) }\end{array}$ & $\begin{array}{c}\text { Laminado unidirecional de } \\
\text { fibra de carbono }\end{array}$ & $\begin{array}{c}\text { Resistência à tração } \\
\text { Modo de ruptura }\end{array}$ \\
\hline 6 & $\begin{array}{c}\text { Sem tratamento } \\
\text { (In natura) }\end{array}$ & $\begin{array}{c}\text { Laminado bi-direcional de } \\
\text { fibra de vidro. }\end{array}$ & $\begin{array}{c}\text { Resistência à tração } \\
\text { Modo de ruptura }\end{array}$ \\
\hline 6 & $\begin{array}{c}\text { Com tratamento } \\
\text { (Autoclavada) }\end{array}$ & $\begin{array}{c}\text { Laminado unidirecional de } \\
\text { fibra de carbono }\end{array}$ & $\begin{array}{c}\text { Resistência à tração } \\
\text { Modo de ruptura }\end{array}$ \\
\hline 6 & $\begin{array}{c}\text { Com tratamento } \\
\text { (Autoclavada) }\end{array}$ & $\begin{array}{c}\text { Laminado bi-direcional de } \\
\text { fibra de vidro. }\end{array}$ & $\begin{array}{c}\text { Resistência à tração } \\
\text { Modo de ruptura }\end{array}$ \\
\hline
\end{tabular}




\subsection{Materiais utilizados na confecção dos Corpos-de-Prova}

\subsubsection{Madeira in natura e autoclavada}

A madeira utilizada na confecção dos corpos de prova in natura e também aqueles levados até a usina de preservação são provenientes de um mesmo lote, que teve o processo de secagem feito ao ar livre, estando a aproximadamente um (1) ano submetido a essa condição. A NBR 7190 [12] define o valor da resistência média à tração da espécie Eucalyptus grandis como sendo de 70,2 MPa, observando a condição de umidade de equilíbrio da madeira igual a 12\%. Na região sul de Santa Catarina, a umidade relativa do ambiente apresenta valores em torno de $80 \%$, logo, a resistência média da madeira deve ser corrigida para essas condições. A Tabela 2 apresenta as classes de umidade da madeira de acordo com a umidade relativa do ambiente.

Tabela 2: Classes de Umidade

\begin{tabular}{c|cc}
\hline Classes de umidade & $\begin{array}{c}\text { Umidade relativa do } \\
\text { ambiente } \mathrm{U}_{\mathrm{amb}}\end{array}$ & $\begin{array}{c}\text { Umidade de equilíbrio } \\
\text { da madeira } \mathrm{U}_{\mathrm{eq}}\end{array}$ \\
\hline 1 & $\leq 65 \%$ & $12 \%$ \\
\hline 2 & $65<\mathrm{U}_{\mathrm{amb}} \leq 75 \%$ & $15 \%$ \\
\hline 3 & $75<\mathrm{U}_{\mathrm{amb}} \leq 85 \%$ & $18 \%$ \\
\hline 4 & $\begin{array}{c}\text { Uamb }>85 \% \text { durante } \\
\text { longos períodos }\end{array}$ & $\geq 25 \%$ \\
\hline
\end{tabular}

Corrigindo o valor da resistência para a umidade de equilíbrio correspondente a região sul que é de $18 \%$, tem-se como resistência média à tração o valor de 59,5 $\mathrm{MPa}$, para a direção paralela ao sentido das fibras. Os corpos de prova de madeira in natura destinados ao processo de autoclave foram tratados industrialmente com o preservante de nome comerciais OSMOSE K33 C, fabricado pela indústria química Montana [13]. Ao todo foram levados 18 corpos de prova para a autoclave. A Figura 6 mostra o aspecto de um corpo de prova autoclavado, quando comparado com aquele que não foi submetido ao tratamento.

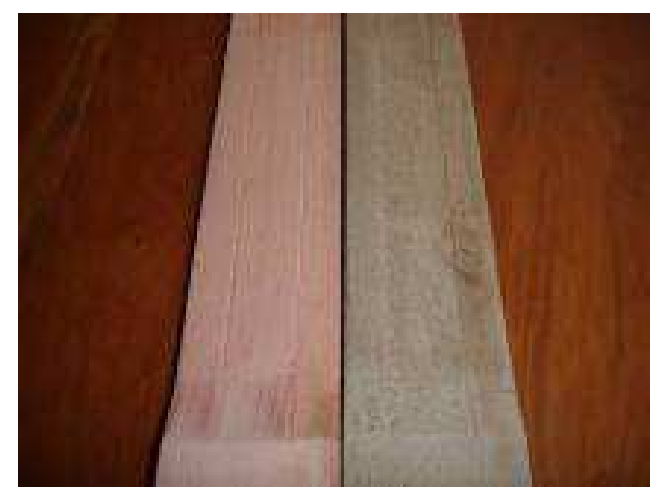

Figura 6: Corpo de prova in natura (à esquerda) e autoclavado (à direita).

O produto OSMOSE K33 é um preservativo de ação fungicida e inseticida classificado quimicamente como Arseniato de Cobre Cromatado (CCA) tipo C - Óxido. Protege a madeira contra o ataque de insetos xilófagos (cupins, brocas, carunchos entre outros), contra fungos apodrecedores e contra a destruição por perfuradores marinhos. O processo de fixação deste preservativo se dá por meio de uma reação de óxi-redução preservativo/madeira (reação química onde ocorre a transferência de elétrons), limitando a solubilidade destes uma vez ocorrida a fixação primária. Devido a sua característica hidrossolúvel, quando introduzido na madeira, seus componentes são micro-distribuídos em todos os tecidos permeáveis do substrato, prolongando sua vida útil (MONTANA [13]). 


\subsubsection{Laminado de Fibra de Carbono}

$\mathrm{O}$ tecido de fibra de carbono utilizado nos ensaios experimentais tem pequena largura quando comparado com uma viga de madeira. O laminado empregado nos ensaios experimentais é do tipo unidirecional, com cinco (5) centímetros de largura (Figura 7). A escolha por um tecido unidirecional deu-se devido à possibilidade de orientar as fibras do reforço na direção a qual ocorre à necessidade da aplicação da força. No caso do ensaio de tração direta, as fibras foram orientadas no sentido paralelo as fibras da madeira, visto que se sabe a direção da tensão atuante, podendo assim alinhar o reforço à tensão.

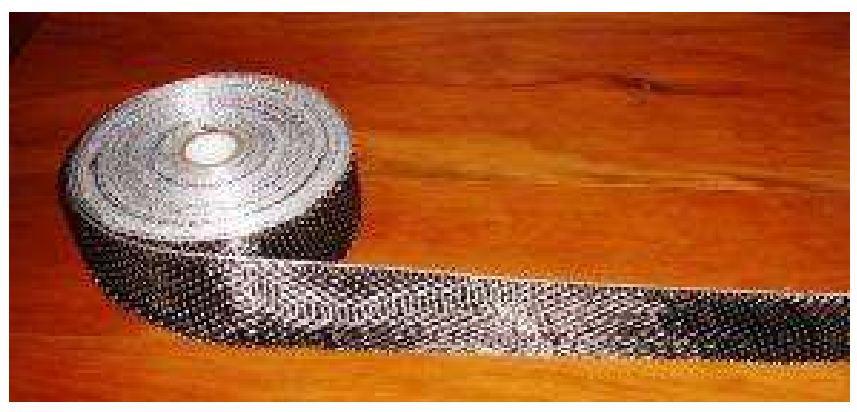

Figura 7: Laminado de fibra de carbono unidirecional.

A Tabela 3 retrata a ficha técnica fornecida pelo fabricante do laminado de fibra de carbono, pontuando as características relevantes desse material. As fibras empregadas foram cortadas com aproximadamente sete (7) centímetros de comprimento e largura de cinco (5) centímetros (área de cola aproximadamente igual a trinta e cinco (35) centímetros quadrados), conforme mostra a Figura 8.

Tabela 3: Ficha técnica do laminado de fibra de carbono. Fonte: TEXIGLASS [14].

\begin{tabular}{|c|c|c|c|c|}
\hline Tipo de Tecelagem & Tela com Trama & & & \\
\hline Parâmetros & Unidade & Mínimo & Nominal & Máximo \\
\hline Peso por m quadrado & $\mathrm{g} / \mathrm{m}^{2}$ & 313 & 348 & 383 \\
\hline Peso por $m$ linear & $\mathrm{g} / \mathrm{m}$ linear & 15,7 & 17,4 & 19,1 \\
\hline Número de Fios de Urdume & Fios $/ \mathrm{cm}$ & 3,80 & 4,00 & 4,20 \\
\hline Número de Fios de Trama & Fios/cm & 2,07 & 2,30 & 2,53 \\
\hline Largura & $\mathrm{mm}$ & 48 & 50 & 52 \\
\hline Comprimento do rolo & $\mathrm{m}$ & 45 & 50 & 55 \\
\hline Tamanho total do rolo & $\mathrm{m}^{2}$ & 2,16 & 2,50 & 2,83 \\
\hline Espessura & $\mathrm{mm}$ & 0,50 & 0,59 & 0,68 \\
\hline \begin{tabular}{|l|} 
Carga de Ruptura Urdume Teórica \\
\end{tabular} & $\mathrm{Kgf} / \mathrm{cm}$ & 544 & 680 & 748 \\
\hline Carga de Ruptura da Trama Teórica & $\mathrm{Kgf} / \mathrm{cm}$ & 8 & 10 & 11 \\
\hline Módulo de Elasticidade Teórico & $\mathrm{Kgf} / \mathrm{cm}^{2}$ & - & 239000 & - \\
\hline \begin{tabular}{|l|} 
Porcentagem de Resina em Peso \\
\end{tabular} & $\%$ & 0 & 0 & 0 \\
\hline
\end{tabular}

Figura 8: Corte da fibra de carbono em tiras $(5 \times 7)$ centímetros. 
A resistência à tração da fibra de carbono é uma das propriedades mais importantes a serem identificadas. Portanto, considerando a direção principal da fibra (urdume) e suas dimensões nominais, a Tabela 3 apresenta a resistência para uma faixa com um (1) centímetro como sendo de 680 kgf.

\subsubsection{Laminado de Fibra de Vidro}

O tecido de fibra de vidro apresentada na Figura 9 é bidirecional e tem 2,5 centímetros de largura. A Tabela 4 retrata a ficha técnica fornecida pelo fabricante da lamina de fibra de vidro, pontuando as características relevantes desse material. Na tabela citada, a largura da lamina aparece como sendo trinta e cinco (35) milímetros. A tensão de ruptura para esse material é de $240 \mathrm{MPa}$. As fibras empregadas foram cortadas com aproximadamente sete (7) centímetros de comprimento e largura de 2,5 centímetros. Para que a área de cola ficasse igual àquela utilizada com a fibra de carbono $\left(35 \mathrm{~cm}^{2}\right)$, foram colados dois pedaços de laminas, um ao lado do outro, em cada seção reforçada do corpo de prova, conforme mostra a Figura 9.

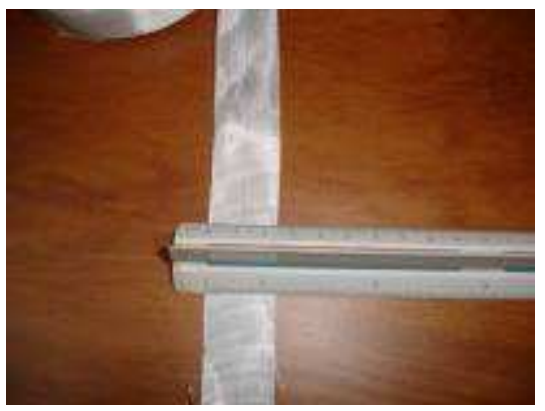

Figura 9: Lamina bidirecional de fibra de vidro.

Tabela 4: Ficha técnica da lamina de fibra de carbono. Fonte: TEXIGLASS [14].

\begin{tabular}{|c|c|c|c|c|}
\hline Tipo de Tecelagem & Tela com Tram & & & \\
\hline Linha d'água central & Sim/Não & Não & NA & \\
\hline Parâmetros & Unidade & Mínimo & Nominal & Máximo \\
\hline Peso por m quadrado & $\mathrm{g} / \mathrm{m}^{2}$ & 216,0 & 240,0 & 264,0 \\
\hline Peso por $m$ linear & $\mathrm{g} / \mathrm{m}$ linear & 7,6 & 8,4 & 9,2 \\
\hline Número de Fios de Urdume & Fios $/ \mathrm{cm}$ & 6 & 6 & 6 \\
\hline Número de Fios de Trama & Fios $/ \mathrm{cm}$ & 5 & 6 & 7 \\
\hline Largura & $\mathrm{mm}$ & 34 & 35 & 36 \\
\hline Comprimento do rolo & $\mathrm{m}$ & 45 & 50 & 55 \\
\hline Tamanho total do rolo & $\mathrm{m}^{2}$ & 1,5 & 1,8 & 2,0 \\
\hline Espessura & $\mathrm{mm}$ & 0,21 & 0,25 & 0,29 \\
\hline Carga de Ruptura do Urdume Teórica & $\mathrm{Kgf} / \mathrm{cm}$ & 48 & 60 & 66 \\
\hline Carga de Ruptura da Trama Teórica & $\mathrm{Kgf} / \mathrm{cm}$ & 48 & 60 & 66 \\
\hline Porcentagem de Resina em Peso & $\%$ & 0 & 0 & 0 \\
\hline
\end{tabular}

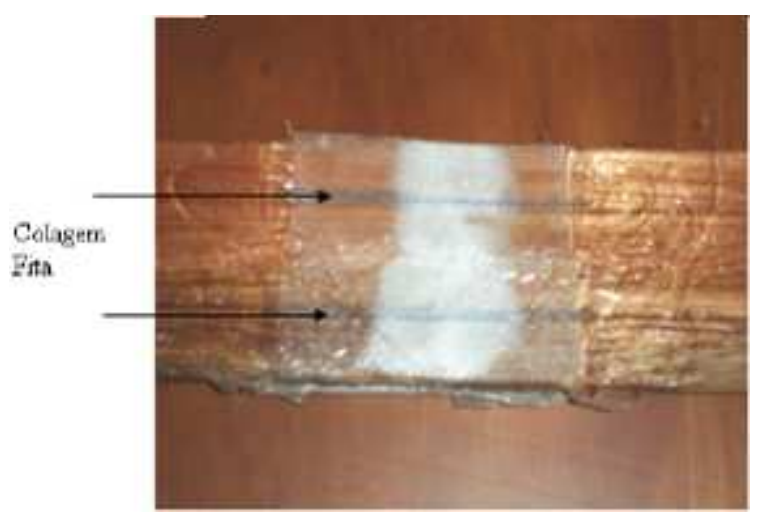

Figura 10: Disposição da lamina de fibra de vidro no corpo de prova. 
A manta de fibra de vidro tem espessura de 0,25 milímetros, enquanto às de carbono possuem espessura de 0,59 milímetros. Para que fosse possível uma comparação mais direta entre os dois tipos de fibra, garantindo a mesma orientação, os corpos de prova reforçados com fibra de vidro foram laminados com duas (2) camadas de fibra em cada lado do reforço.

\subsubsection{Sistema Epóxi}

O sistema epóxi utilizado é formado por resina e endurecedor, sendo comercializado sob o nome de AR-300 e AH-30, respectivamente [15]. A resina epoxi AR-300 foi desenvolvida para usos nos processos de fabricação em fibra de vidro, de carbono e de aramida. São de fácil molhabilidade durante o uso e possuem viscosidade baixa, características estas que permitem um fácil manuseio durante o processo de impregnação. $\mathrm{O}$ endurecedor utilizado foi adicionado à resina na proporção de 100 partes de resina para 33 partes de endurecedor por peso, de acordo com o recomendado pelo fabricante. A mistura e a cura da resina foram realizadas na temperatura ambiente. A formulação do sistema não desenvolve superfície pegajosa após o processo de cura, possibilitando laminações sucessivas de outros reforços. As propriedades do sistema de laminação, incluindo o período de tempo em que a resina catalisada mantém uma viscosidade suficientemente baixa para ser usada no processamento, encontram-se na Tabela 5.

Tabela 5: Propriedades do sistema de laminação com AR-300. Fonte: [15].

\begin{tabular}{c|c}
\hline \multicolumn{2}{c}{ Endurecedor AH-30 } \\
\hline \multicolumn{2}{c}{ Propriedades após a mistura a $25^{\circ} \mathrm{C}$} \\
\hline Viscosidade (CPS) & 900 \\
\hline Tempo de trabalho (Pot-life), min & 30 \\
\hline Tempo de gel (Gel Time 150g, 25 $\left.{ }^{\circ} \mathrm{C}\right)$, min & 30 \\
\hline Proporção da mistura por peso & $100: 33$ \\
\hline Propriedades físicas e mecânicas após a cura total \\
\hline Elongação (\%) & 3,2 \\
\hline Contração & $<0.002$ \\
\hline Módulo de elasticidade (GPa) & 2,6 \\
\hline Resistência à flexão (MPa) & 9,4 \\
\hline Resistência à compressão $(\mathrm{MPa})$ & 13,9 \\
\hline
\end{tabular}

\section{CONFECÇÃO DOS CORPOS-DE-PROVA}

Os corpos de prova de madeira foram previamente beneficiados de acordo com as dimensões previstas na NBR 7190 [12]. Após essa etapa, estes foram classificados para os testes in natura e autoclavado. Corpos de prova com defeitos do tipo nós ou rachaduras foram descartados. As dezoito amostras separadas para serem submetidas ao processo de autoclave foram levadas à usina de preservação e tratadas com o produto OSMOSE K33 C. O processo de autoclave deixou a madeira bastante úmida com a impregnação dos produtos, por isso esses mesmos corpos de prova foram colocados em uma estufa com temperatura de $100^{\circ} \mathrm{C}$ durante aproximadamente 7 (sete) dias, antes de ser efetuada a laminação. Dos 36 corpos de prova confeccionados, 12 foram destinados ao ensaio de tração sem qualquer tipo de reforço ou corte. Os restantes foram cortados na região central para posterior ligação por meio de fibra e adesivo. A ligação entre as duas partes de um mesmo corpo de prova foi feita somente por meio de fibras com comprimento de sete (7) centímetros laminadas com adesivo epóxi. Esse comprimento foi adotado segundo estudos feitos por FIORELLI [9]. O mesmo foi feito com as fibras de vidro. As fibras foram coladas nos dois lados do corpo de prova, sendo a etapa de laminação apresentada na Figura 11. 


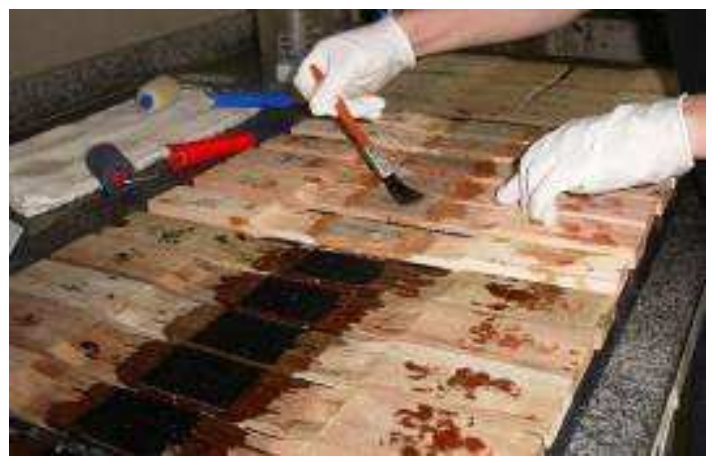

Figura 11: Processo de laminação natural com fibra adesivo.

A colagem da fibra à madeira deu-se por consolidação simultânea, ou seja, ao mesmo tempo em que a resina cura, a fibra é consolidada no contato com a madeira. Segundo CARVALHO [2], a consolidação simultânea possui como vantagem a redução do número de operações necessárias durante o processo. A fabricante da resina recomenda três (3) dias de cura para o sistema, no entanto, as amostras preparadas tiveram um período de sete (7) dias para a cura da resina e somente após isso foram feitos os ensaios de tração.

\subsection{Instrumentação}

Os corpos de prova foram submetidos a ensaios destrutivos de tração em Máquina de Ensaio Universal EMIC, capacidade 60 toneladas, com velocidade constante de deformação igual a $2 \mathrm{~mm} / \mathrm{min}$. O ensaio de tração foi conduzido com carga aplicada uniaxialmente de maneira suficientemente lenta. Com este ensaio, foi possível medir o valor da força máxima para que ocorresse a ruptura da fibra, madeira ou adesivo. A Figura 12 mostra a realização do ensaio nas amostras sem reforço e com reforço.
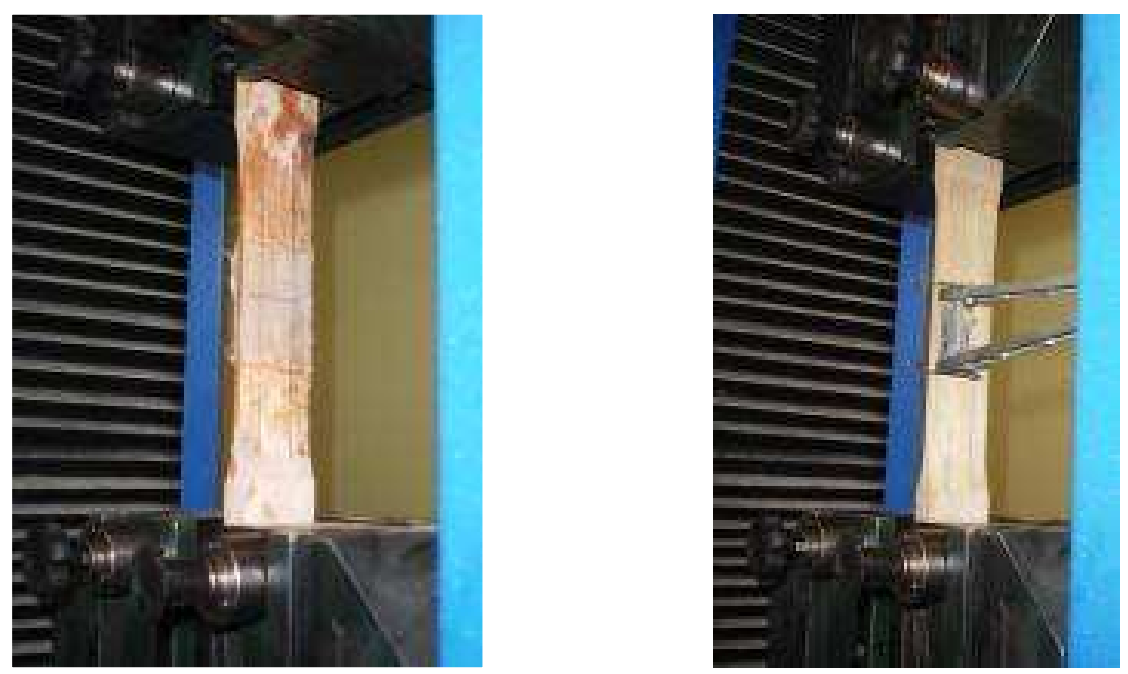

Figura 12: Ensaio de tração em madeira com e sem reforço.

\section{APRESENTAÇÃO E DISCUSSÃO DOS RESULTADOS}

Nos experimentos foram realizados ensaios de tração direta em corpos de prova de madeira sem reforço in natura e autoclavada e em corpos de prova de madeira reforçados com fibra de vidro e de carbono. Com esses ensaios foram possíveis obter o valor das máximas tensões responsáveis pela ruptura da fibra da madeira ou do adesivo. 


\subsection{Tração em madeira sem reforço in natura}

O diagrama tensão e deformação das seis amostras submetidas à tração mostraram que a madeira possui um comportamento elástico-linear até próximo a ruptura. Observou-se, no entanto, que algumas amostras apresentaram deformações negativas quando a sua tensão chegou próximo a $50 \mathrm{MPa}$. Isso ocorreu, provavelmente, devido a alguma falha interna da madeira, com o rompimento localizado de uma fibra ou nó, fazendo com que o extensômetro instalado em apenas um dos lados do corpo de prova registrasse um deslocamento negativo, voltando a registrar deslocamentos positivos com o aumento da carga até a ruptura. A Tabela 12 mostra a resistência à tração de cada amostra, assim como o valor do módulo de módulo de elasticidade tangente inicial e massa.

Tabela 12: Propriedades apresentadas pelos corpos de prova in natura

\begin{tabular}{c|c|c|c|c}
\hline Corpo de Prova & Massa $(\mathrm{g})$ & $\begin{array}{c}\text { Força } \\
\text { Máxima }(\mathrm{kN})\end{array}$ & $\begin{array}{c}\text { Resistência à } \\
\text { Tração }(\mathrm{MPa}\end{array}$ & $\begin{array}{c}\text { Módulo de } \\
\text { Elasticidade (MPa) }\end{array}$ \\
\hline CP 1 & 171,10 & 28,31 & 81,1 & 16189 \\
CP 2 & 141,20 & 25,97 & 71,7 & 18630 \\
CP 3 & 165,70 & 27,85 & 82,4 & 14543 \\
CP 4 & 158,90 & 21,03 & 57,3 & 24488 \\
CP 5 & 152,00 & 21,32 & 58,5 & 20007 \\
CP 6 & 145,40 & 18,27 & 55,5 & 13046 \\
\hline Média & 155,72 & 23,79 & 67,75 & 17817,17 \\
Desvio Padrão & 11,64 & 4,14 & 12,27 & 4149,49 \\
\hline Coef. Variação (\%) & 7,48 & 17,42 & 18,12 & 23,29 \\
\hline
\end{tabular}

Conforme a Tabela 12, a resistência à tração média das amostras foi de $67,75 \mathrm{MPa}$ e o desvio padrão de $12,27 \mathrm{MPa}$, valor este superior em $12 \%$ da mencionada em norma corrigida para a umidade de $18 \%$. A Tabela 13 mostra o modo de ruptura de cada corpo de prova durante o ensaio. Algumas amostras iniciaram o processo de ruptura na região comprimida pela garra da máquina de ensaio, como é o caso do CP 2. A partir da compressão, iniciou-se um processo de rotação no mesmo influenciando a ruptura do corpo de prova.

Tabela 13: Modo de ruptura da madeira in natura

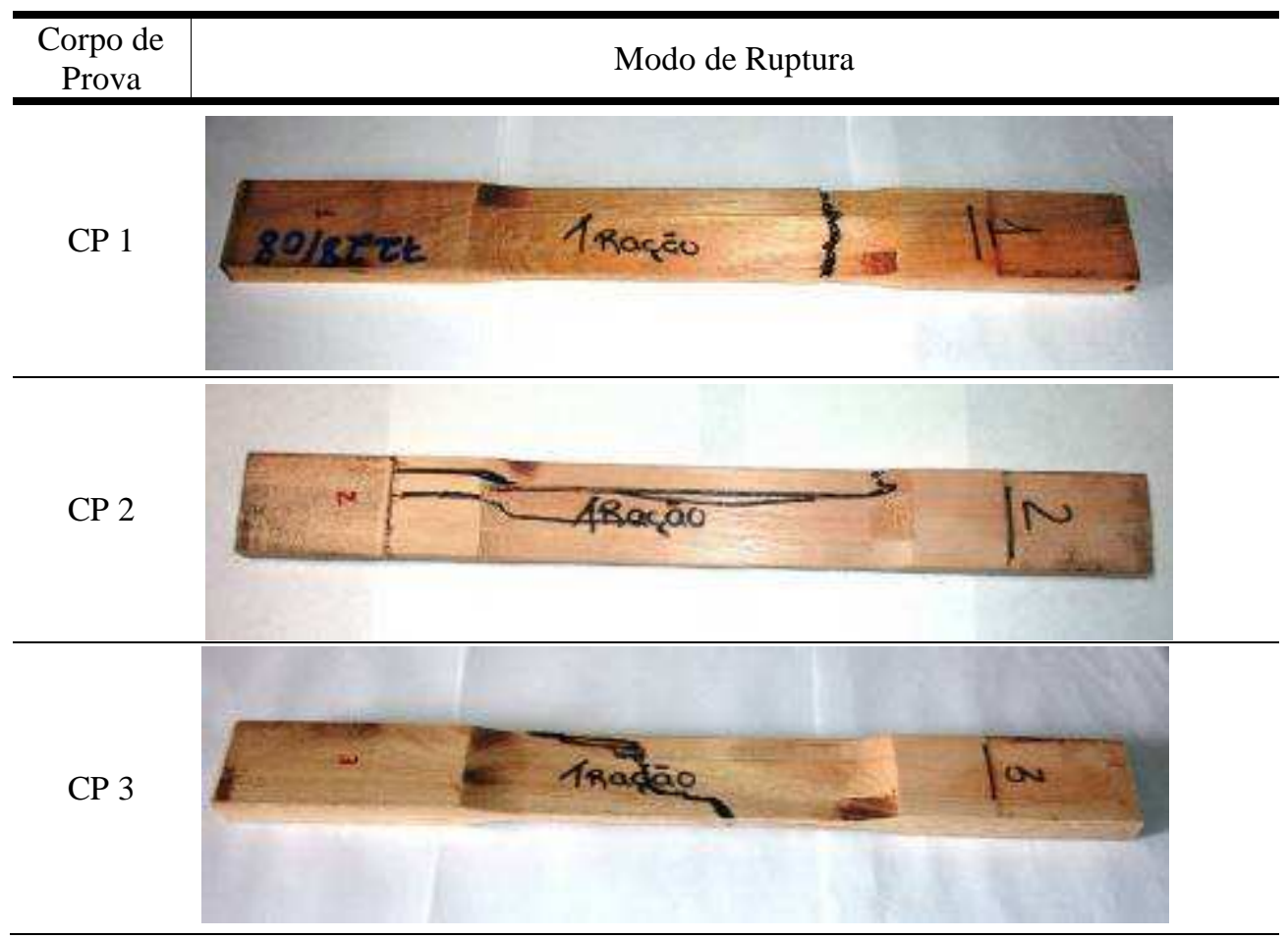




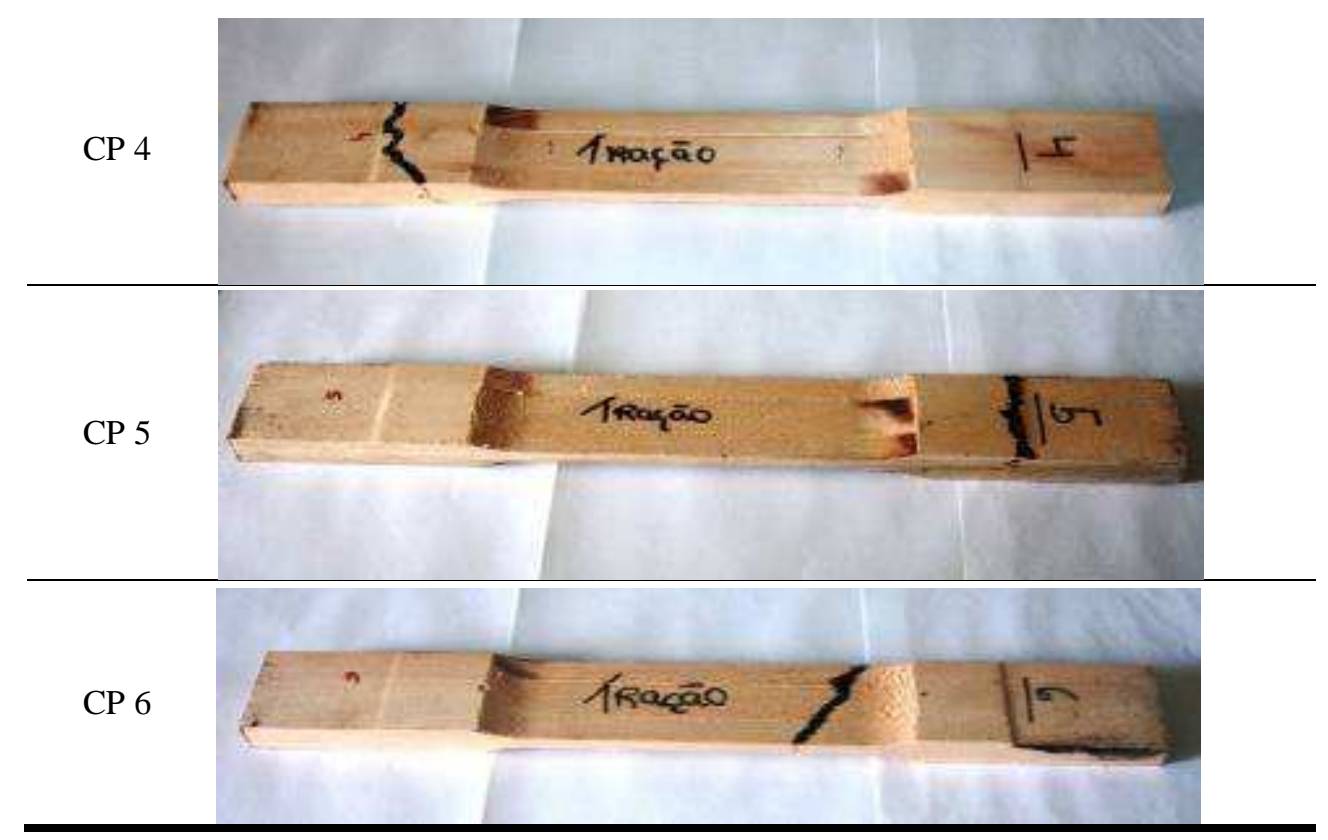

\subsection{Tração em madeira sem reforço autoclavada}

Foram realizados ensaios de tração direta em seis amostras de madeira autoclavada, cujo comportamento da tensão e deformação se assemelhou com os obtidos nas amostras in natura, ou seja, a madeira apresentou um comportamento elástico-linear até próximo a ruptura. A Tabela 14 mostra a resistência à tração de cada amostra autoclavada, assim como seu módulo de elasticidade e massa.

Tabela 14: Propriedades apresentadas pelos corpos de prova autoclavados

\begin{tabular}{c|c|c|c|c}
\hline Corpo de Prova & Massa $(\mathrm{g})$ & $\begin{array}{c}\text { Força } \\
\text { Máxima }(\mathrm{kN})\end{array}$ & $\begin{array}{c}\text { Resistência à } \\
\text { Tração }(\mathrm{MPa})\end{array}$ & $\begin{array}{c}\text { Módulo de } \\
\text { Elasticidade }(\mathrm{MPa})\end{array}$ \\
\hline CP 1 & 127,90 & 14,66 & 50,1 & 23178 \\
CP 2 & 164,20 & 25,25 & 83,6 & 24286 \\
CP 3 & 184,40 & 32,27 & 110,1 & 26433 \\
CP 4 & 134,00 & 15,21 & 51,4 & 18907 \\
CP 5 & 149,10 & 20 & 70,2 & 11874 \\
CP 6 & 137,90 & 27,68 & 94,4 & 20354 \\
\hline Média & 149,58 & 22,51 & 76,63 & 20838,67 \\
Desvio Padrão & 21,33 & 7,08 & 23,94 & 5157,22 \\
\hline Coef. Variação (\%) & 14,26 & 31,46 & 31,24 & 24,75 \\
\hline
\end{tabular}

Os resultados de resistência à tração da madeira autoclavada ficou acima dos valores de referência sugeridos pela norma NBR 7190 [12], corrigida a umidade de equilíbrio. Num ensaio preliminar a madeira in natura foi submetida ao processo de autoclave e depois de aproximadamente 15 dias foram feitos os ensaios de tração, onde o valor da resistência média foi de 49,28 MPa. Para os ensaios definitivos, as amostras foram colocadas em estufa para que pudessem perder parte da umidade adquirida na autoclave. Após esta colocação os resultados de resistência à tração tiveram valores superiores, sendo possível concluir com isso que a umidade tem uma influência significativa na resistência da madeira. A Tabela 15 mostra o modo de ruptura de cada corpo de prova durante o ensaio. Verificou-se que em algumas amostras a ruptura aconteceu na região comprimida pela garra da máquina de ensaio, como mostra a imagem do CP 1 . Não houve mudança significativa na resistência à tração do Eucalyptus grandis in natura e autoclavada. Mesmo com os resultados de resistência à tração indicando valores superiores para a madeira in natura e autoclavada, concluindo-se que a umidade foi responsável pela variação entre ambos. Os corpos de prova in natura e autoclavado foram ensaiados em dias diferentes, além de passarem por processos de secagem diferentes. A NBR 7190 [12] recomenda 12.813 MPa para o valor do módulo de elasticidade da espécie Eucalyptus grandis, observando a condição de umidade de equilíbrio da madeira igual a 12\%. Para a região sul de Santa Catarina, com umidade 
relativa do ambiente em torno de $80 \%$, o módulo de elasticidade médio da madeira foi corrigido, onde com a correção passou a ser de $11.440 \mathrm{MPa}$. Concluiu-se que os módulos de elasticidade apresentados nos ensaios experimentais mostraram-se superiores ao especificado em norma NBR 7190 [12].

Tabela 15: Propriedades apresentadas pelos corpos de prova autoclavados

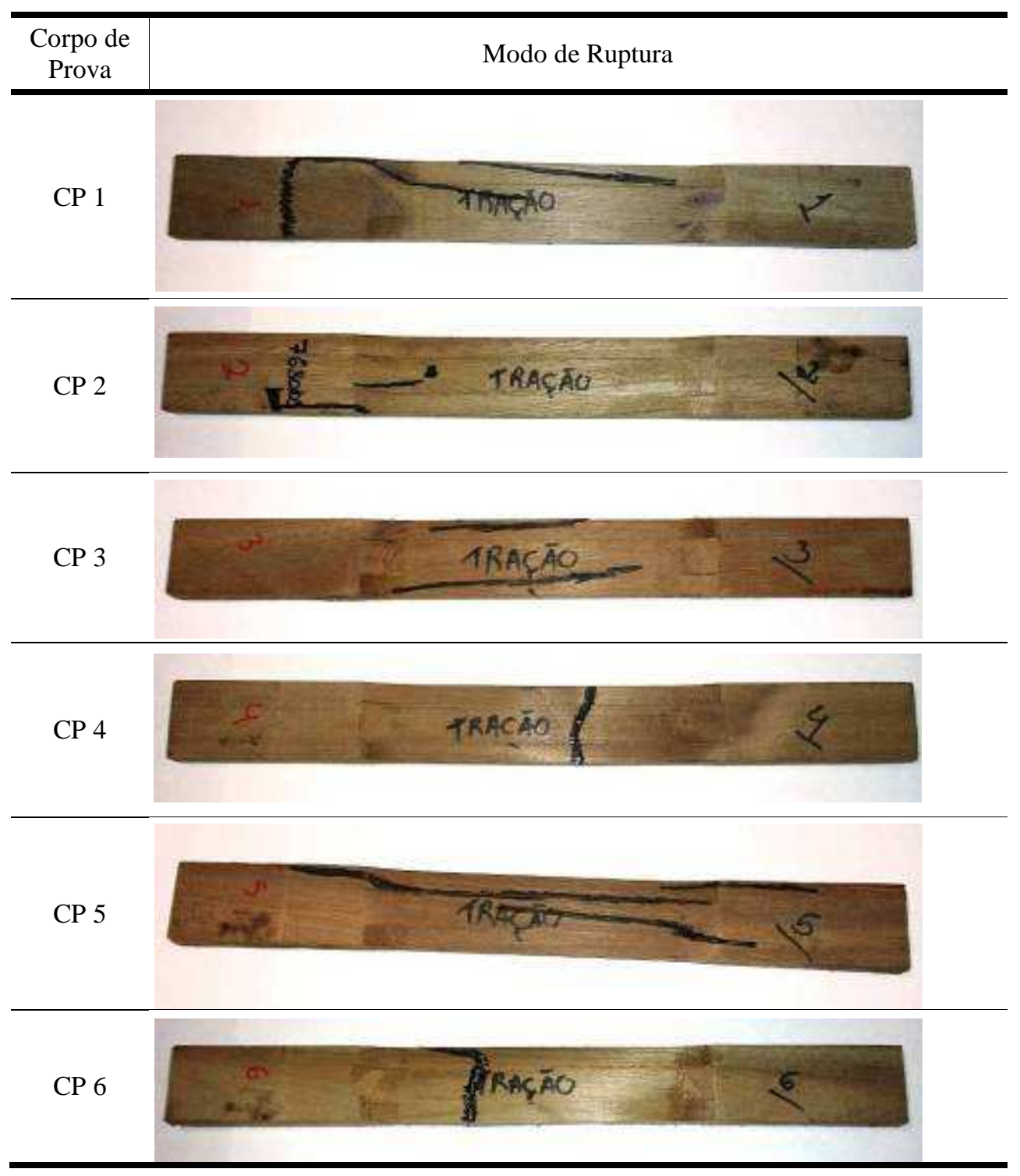

\subsection{Tração em madeira com reforço de fibra de vidro}

Os corpos de prova reforçados com duas camadas de fibra de vidro com 0,25 milímetros de espessura apresentaram um comportamento visco elástico, comportamento este típico de materiais compósitos poliméricos. Esses corpos-de-prova apresentaram deformações significativas, quando comparados com a madeira sem reforço, cuja ruptura foi frágil e com uma pequena zona de acomodação quando atingida uma força de tração próxima a quatro (4) KN. As deformações na região anterior a zona de acomodação acontecem diretamente no polímero, pois no processo de laminação as duas faces cortadas do corpo de prova acabaram ficando coladas com resina epóxi. Quando a resina rompe a deformação passa a depender do conjunto formado pela fibra e resina aderido ao substrato. Nas duas amostras com fibras de vidro in natura e autoclavada foram considerados apenas cinco (5) cinco corpos de prova devido a problemas durante a laminação, onde algumas amostras tiveram que ser descartados. Não foram constatadas diferenças significativas quanto ao substrato in natura e autoclavado. Pode ser observado, na Tabela 16, que levando em consideração o desvio padrão das amostras, não há diferença entre o substrato formado por madeira in natura e autoclavada. 
Tabela 16: Propriedades apresentadas pelos CP's reforçados com fibra de vidro

\begin{tabular}{c|c|c|c|c}
\hline \multirow{2}{*}{ Corpo de Prova } & \multicolumn{2}{|c|}{ Madeira in natura } & \multicolumn{2}{c}{ Madeira autoclavada } \\
\cline { 2 - 5 } & Força Máxima $(\mathrm{kN})$ & $\begin{array}{r}\text { Resistência à } \\
\text { tração }(\mathrm{MPa})\end{array}$ & Força Máxima $(\mathrm{kN})$ & $\begin{array}{c}\text { Resistência } \\
\text { à tração }(\mathrm{MPa})\end{array}$ \\
\hline CP 1 & 14,10 & 40,29 & 12,70 & 36,29 \\
CP 2 & 9,80 & 28,00 & 15,10 & 43,14 \\
CP 3 & 9,80 & 28,00 & 10,90 & 31,14 \\
CP 4 & 15,50 & 44,29 & 11,50 & 32,86 \\
CP 5 & 17,40 & 49,71 & 15,80 & 45,14 \\
\hline Média & 13,32 & 38,06 & 13,20 & 37,71 \\
\hline Desvio Padrão & 3,42 & 9,77 & 2,17 & 6,19 \\
\hline Coef. Variação (\%) & \multicolumn{2}{|c}{16,42} \\
\hline
\end{tabular}

Após a ruptura dos corpos de prova observou-se que o adesivo epóxi não obteve boa aderência à fibra de vidro utilizada. $\mathrm{O}$ fator determinante da aderência entre o substrato e a madeira pode ser afetado pela formação de bolhas de ar entre o substrato/adesivo e a fibra/adesivo. Esse fenômeno foi observado nos corpos de prova reforçados com fibra de vidro. As Tabelas 17 e 18 mostram a imagem da forma de ruptura dos corpos de prova, assim como a descrição dos prováveis modos de ruptura ocorrida, se por tração, cisalhamento ou adesiva.

Tabela 17: Ruptura dos CP's in natura reforçados com fibra de vidro

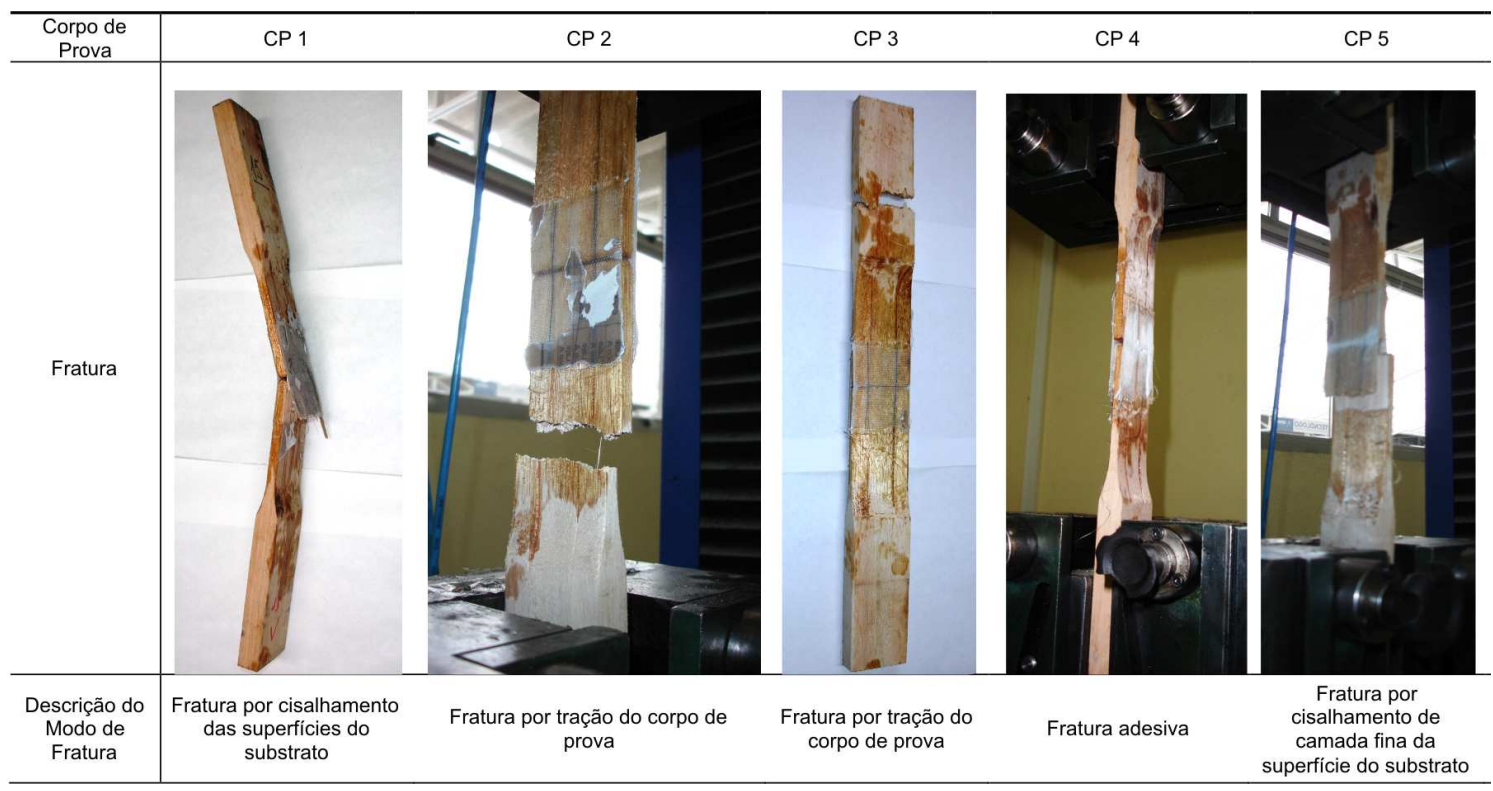


Tabela 18: Ruptura dos CP's autoclavados reforçados com fibra de vidro

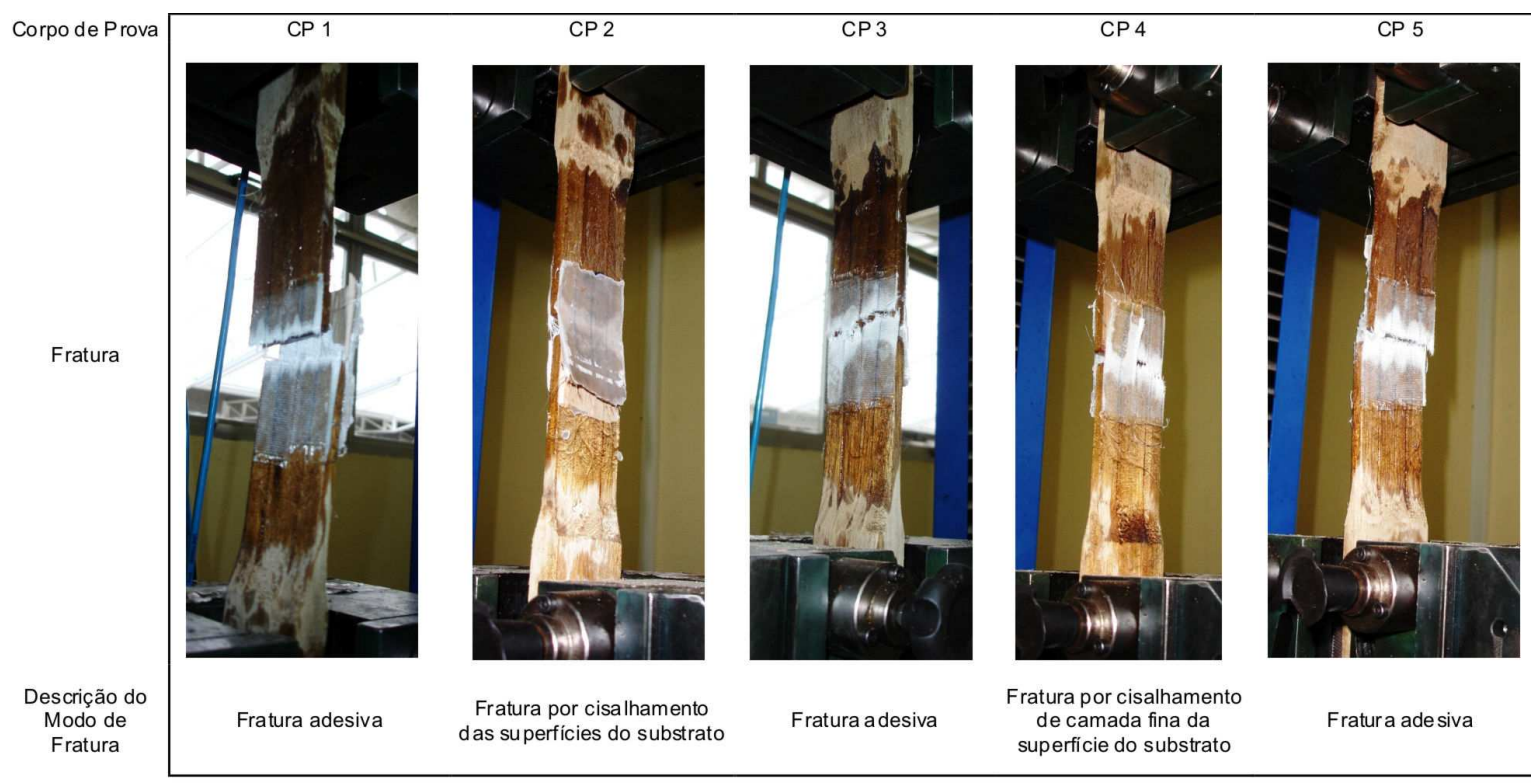

Estudos realizados por OLIVEIRA [16] analisaram a influência do preservante arseniato de cobre cromatado (CCA) utilizado em madeiras que posteriormente foram transformadas em madeira laminada colada (MLC) por meio de emendas dentadas denominadas de finger-joint. As colagens foram realizadas antes e após o tratamento preservativo utilizando-se o adesivo bi-componente Wonderbond EPI EL-70, juntamente com o endurecedor EPI WS 742 na proporção de 100 partes do adesivo para 20 partes do endurecedor. Após sete dias de cura do adesivo, os testes de resistência à tração paralela realizados mostraram resultados equivalentes, não apresentando diferenças estaticamente significativas na resistência de colagem antes e após o tratamento preservativo. Concluiu-se, portanto, que os resultados analisados nesta pesquisa e os obtidos por OLIVEIRA [16] são similares.

\subsection{Tração em madeira com reforço de fibra de carbono}

Os corpos de prova reforçados com fibra de carbono de 0,59 milímetros de espessura apresentaram um comportamento bi-linear, ou seja, duas regiões elásticas distintas. Os corpos de prova caracterizaram-se por atingir níveis de resistência à tração que, praticamente, recuperou a capacidade resistente original da madeira. Novamente não foram constatadas diferenças significativas quanto ao substrato in natura e autoclavado. A Tabela 19 apresenta os valores médios e máximos das tensões nas amostras.

Tabela 19: Propriedades dos CP's reforçados com fibra de carbono

\begin{tabular}{c|c|c|c|c}
\hline \multirow{2}{*}{ Corpo de Prova } & \multicolumn{2}{|c|}{ Madeira in natura } & \multicolumn{2}{c}{ Madeira autoclavada } \\
\cline { 2 - 5 } & Força Máxima $(\mathrm{kN})$ & $\begin{array}{r}\text { Resistência à } \\
\text { Tração }(\mathrm{MPa})\end{array}$ & Força Máxima (kN) & $\begin{array}{c}\text { Resistência à } \\
\text { Tração (MPa) }\end{array}$ \\
\hline CP 1 & 15,70 & 44,86 & 22,50 & 64,29 \\
CP 2 & 20,20 & 57,71 & 20,10 & 57,43 \\
CP 3 & 25,90 & 74,00 & 31,40 & 89,71 \\
CP 4 & 16,60 & 47,43 & 20,10 & 57,43 \\
CP 5 & 24,00 & 68,57 & 20,30 & 58,00 \\
CP 6 & 28,50 & 81,43 & 28,70 & 82,00 \\
\hline Média & 21,82 & 62,33 & 23,85 & 68,14 \\
Desvio Padrão & 5,16 & 14,76 & 4,96 & 14,18 \\
\hline Coef. Variação (\%) & \multicolumn{2}{|c|}{23,67} & \\
\hline
\end{tabular}

Analisou-se a forma de ruptura dos corpos de prova, observou-se que o adesivo epóxi obteve boa aderência à fibra de carbono utilizada nos experimentos. As Tabelas 20 e 21 mostram a forma de ruptura dos corpos de prova, assim como a descrição do modo de ruptura considerada. Grande parte das fraturas ocorreu 
por tração nos corpos de prova ou cisalhamento de uma camada do substrato, o que indica a boa aderência conseguida em entre a fibra, o adesivo e a madeira.

Tabela 20: Ruptura dos corpos de prova in natura reforçados com fibra de carbono

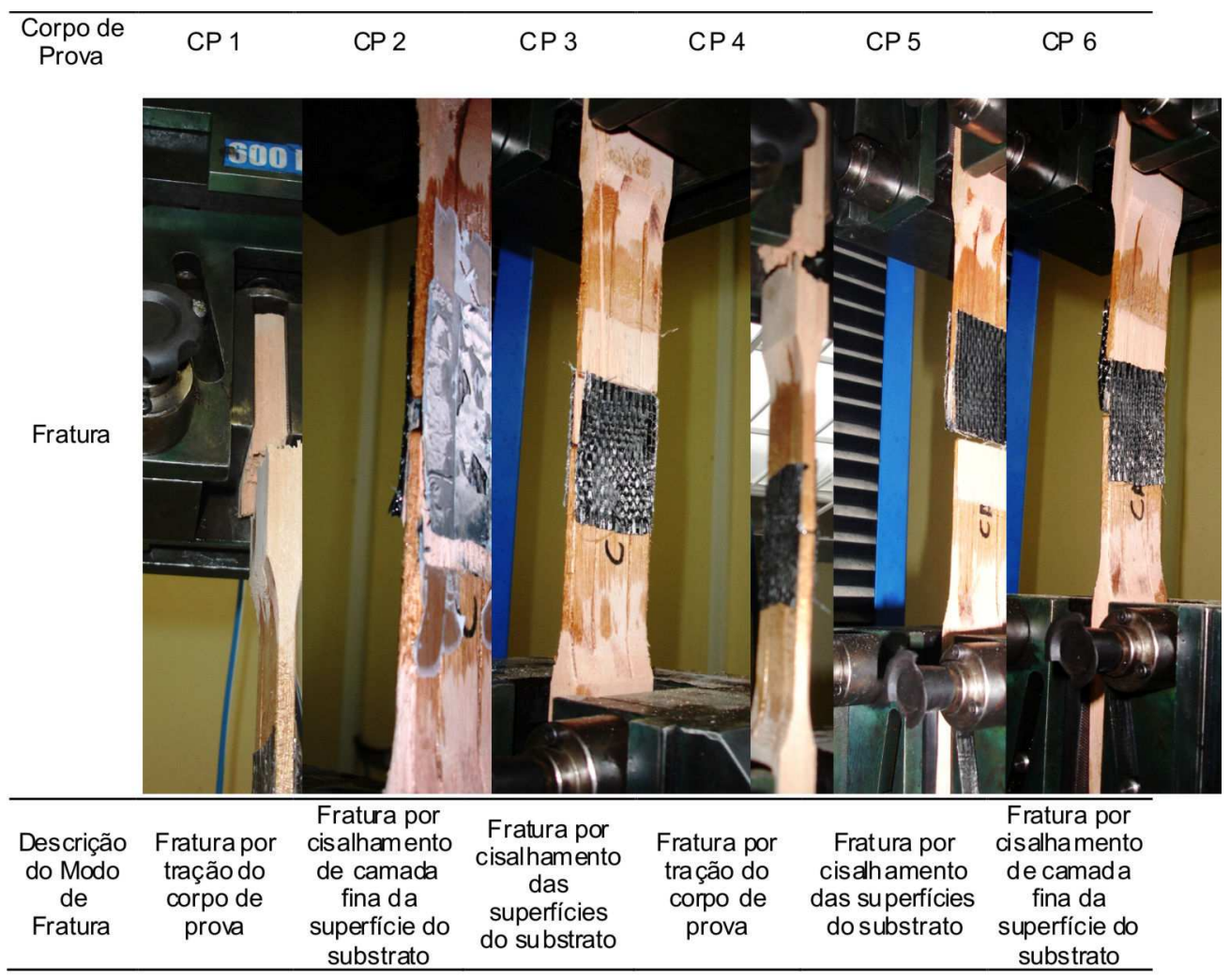

Tabela 21: Ruptura dos corpos de prova autoclavados reforçados com fibra de carbono

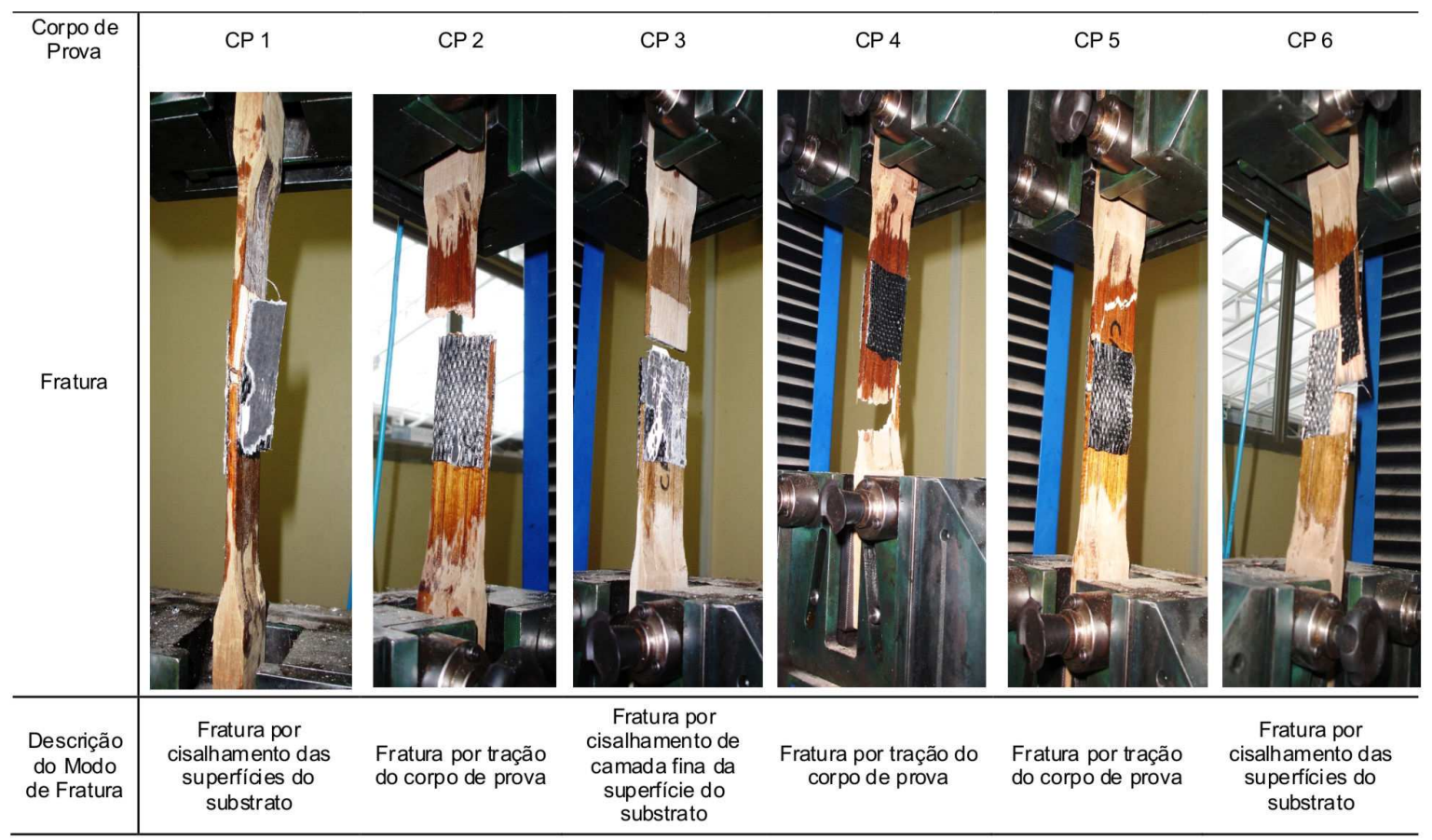




\section{CONCLUSÕES}

Dos estudos teóricos e experimentais realizados concluiu-se que as fibras são viáveis tecnicamente no reforço das estruturas em madeira, pois recuperam boa parte da resistência desta. A resina epóxi utilizada mostrou-se trabalhável durante o processo de laminação e com boa adesividade a madeira de Eucalyptus grandis. Com relação à fibra de vidro, houve pouca aderência ao substrato, mas alguns fatores podem ter influenciado nessa adesividade, como o fato de se laminar duas camadas sucessivas de fibra de vidro, podendo aprisionar bolhas de ar internas nas interfaces, traduzindo-se em falhas de contato. Tanto a fibra de vidro como a de carbono foram submetidas à desaeração quando laminadas, a fim de diminuir a incorporação de ar proporcionada pela laminação manual. Os resultados com fibra de carbono foram bastante promissores, onde se verificou uma recuperação de $92 \%$ na resistência à tração média da madeira reforçada com fibra, quando comparados com a resistência à tração in natura sem fratura. Praticamente a mesma recuperação aconteceu na madeira autoclavada. Com relação à recuperação proporcionada pela fibra de vidro, o percentual ficou em torno de 50\%. A observação do comportamento do substrato permitiu concluir que não existe diferença significativa entre a aderência da madeira in natura e autoclavada, mas pode existir uma diminuição na resistência de aderência do substrato com a umidade, como é o caso da condição da madeira logo após o tratamento em autoclave. A avaliação da associação do adesivo epóxi à fibra de carbono e fibra de vidro com o objetivo de reforçar as estruturas de madeira é possível desde que controladas as variáveis que interferem no processo como: a incorporação de ar nas interfaces, umidade do substrato e adesivo compatível com o reforço utilizado.

\section{BIBLIOGRAFIA}

[1] MIOTTO, J. L.; DIAS, A.A., "Reforço e recuperação de estruturas de madeira", In: Semina: Ciências Exatas e Tecnológicas, pp.163-174, Londrina, Paraná, v. 27, n. 2, jul./dez, 2006.

[2] CARVALHO, R. F., Compósitos de fibras de sisal para uso em reforço de estruturas de madeira. Tese de D. Sc., USP, São Carlos, SP, Brasil, 2005.

[3] ILHARCO, T., "Intervenção em estruturas de madeira do centro histórico de Porto, património mundial da UNESCO”. In: Congresso Luso-Moçambicano de Engenharia, Maputo, Moçambique, 2008.

[4] MACHADO, A. de P., Reforço de estruturas de concreto armado com fibras de carbono. $1^{\mathrm{a}}$ ed., São Paulo, PINI, 2002.

[5] FIORELLI, J.; DIAS, A. A., "Método para avaliação da degradação de elementos construtivos de pontes de madeira: estudo de caso na região oeste paulista". Revista Madeira, n.17, São Carlos, set./dez., 2005.

[6] CRUZ, H., "Patologia, avaliação e conservação de estruturas de madeira". In: Curso livre internacional de património, Santarém, 2001.

[7] FEIO, A. J. de O., Inspecção e Diagnóstico e estruturas históricas de madeira: correlações com métodos não destrutivos e comportamento estrutura, Tese de D.Sc., Uminho, Guimarães, Portugal, 2005.

[8] ROMAGNANO, L. F. T., Instrumentos de gestão ambiental integrada: diretrizes para o controle de cupins subterrâneos em ambientes construídos, Tese de M. Sc., IPT, São Paulo, Brasil, 2004.

[9] FIORELLI, Juliano., Utilização de fibras de carbono e de fibras de vidro para reforço de vigas de madeir,. Tese de M. Sc., USP, São Carlos, São Paulo, 2002.

[10] CUNHA, J., SOUZA J. D. A., "Avaliação estrutural de peças de madeira reforçadas por fibras de carbono”. Revista de Engenharia Civil, n. 20, Guimarães, Maio, 2004.

[11] SIKA ITALIA, http//www.sika.com. Acessado em 12 outubro de 2008.

[12] NBR 7190 , Projeto de Estruturas de Madeira, Rio de Janeiro, ABNT - Associação Brasileira de Normas Técnicas, 1997.

[13] MONTANA QUÍMICA S.A., Boletim Técnico: Osmose K33 C. São Paulo, 2008. 
[14] TEXIGLASS, http//www.texiglass.com.br. Acessado em 14 setembro 2008.

[15] BARRACUDA, http//www.barracudatec.com.br. Acessado em 14 setembro de 2008.

[16] OLIVEIRA, Maurício Pinheiro., "Influência do tratamento preservativo na colagem em emendas fingerjoint”, Revista da Madeira, n.116, Curitiba, pp. 92-94, Set., 2008. 